\title{
De novo basilar tip aneurysm. Case report and literature review
}

\author{
M.T.M. Suzuki; G.B. Aguiar; M. Jory; M.L.M. Conti and J.C.E. Veiga
}

Santa Casa Medical School. Department of Surgery. Division of Neurosurgery. São Paulo. Brazil.

\section{Summary}

The de novo aneurysms are the formation of new aneurysms in a location previously observed to be normal by a cerebral angiography or direct microsurgical exploration. In this report, we present a review of the theme and describe a case of a ruptured de novo basilar tip aneurysm in a patient previously treated with carotid occlusion for a giant intracavernous aneurysm and microsurgical clipping of contralateral posterior communicating artery aneurysm.

KEY WORDS. Basilar artery, De novo aneurysm, Subarachnoid hemorrhage

Aneurisma de novo del topo basilar. Descripción de un caso y revisión de la literatura

\section{Resumen}

Se llaman aneurismas de novo a la formación de aneurismas en una región previamente normal, observado y documentado por una angiografía cerebral o por la exploración microquirúrgica directa. En este trabajo, se presenta una revisión de la literatura sobre el tema y la descripción de un caso de ruptura de un aneurisma de novo en la arteria basilar en un paciente que previamente fue tratado con la oclusión de la arteria carótida para el tratamiento de un aneurisma gigante intracavernoso de un lado y el clipaje microquirúrgico de un aneurisma en la arteria comunicante posterior contralateral.

PALABRAS CLAVE. Arteria basilar. Aneurisma de novo. Hemorragia subaracnóidea.

\section{Introduction}

The definition of the de novo aneurysm is the forma-

Recibido: 28-09-10. Aceptado: 12-02-11 tion of a new aneurysm in a location previously normal by an angiography or direct surgical exploration ${ }^{3,6,14,15}$. To be considered a de novo aneurysm, it must be located at a site remote from the original aneurysm ${ }^{6,14,15}$.

Despite advances in neuroimaging studies in the past two decades, de novo formations are still rare and underestimated among neurosurgeons and neuroradilogists. Even large trials, such the recent International Subarachnoid Aneurysm Trial (ISAT) do not estimate the real incidence of the de novo entity ${ }^{10}$. Misdiagnosis may be related to the lack of angiographic studies in patients labeled as cured after surgery or embolization of a previous aneurysm.

The most common location of the de novo aneurysm formation is the anterior circulation ${ }^{8}$. Posterior circulation de novo aneurysms, such as our case, are extremely rare and there is no data in the literature to indicate the actual number of cases reported until now.

We report on a case of basilar tip de novo aneurysm in an elderly woman previously treated with microsurgical clipping of a right posterior communicating artery aneurysm and carotid occlusion for a giant contralateral intracavernous aneurysm.

\section{Case report}

A 62-year-old woman experienced the worst headache of her life during rest, followed by a brief lost of consciousness. She was admitted to the emergency room awake, fully conscious, complaining of a holocranian headache. She had complete palsy of the III and VI nerves on the left side, as a cavernous sinus syndrome. There was no history of smoking, hypertension, previous neurological diseases or other associated risks for subarachnoid hemorrhage. The CT scan demonstrated a hyperdense lesion in the left carorid artery, resembling a giant intracavernous aneurysm. Cerebral angiography revealed a right carotid aneurysm in the communicating segment (Figure 1A) and a giant intracavernous carotid artery aneurysm in the left side

Abbreviations. CT: computed tomography. SAH: subarachnoid hemorrhage. MRI: magnetic resonance imaging. 

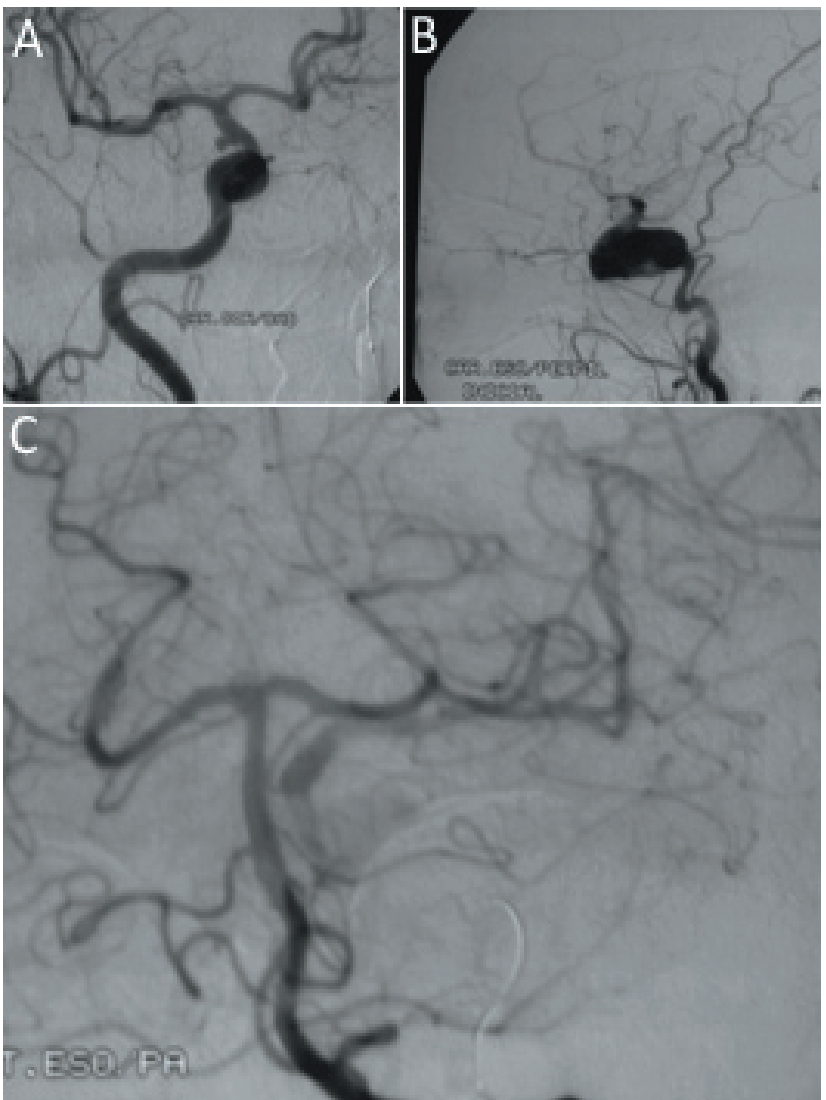

Figure 1. Angiography showing: A - Right PComA aneurysm and B - Left giant carotid aneurysms; $C$ - Left vertebral selective angiography, during balloon occlusion test, showing no basilar aneuysms.

(Figure 1B). No abnormalities were observed in the posterior circulation after injection of contrast in the left vertebral artery (Figure 1C).

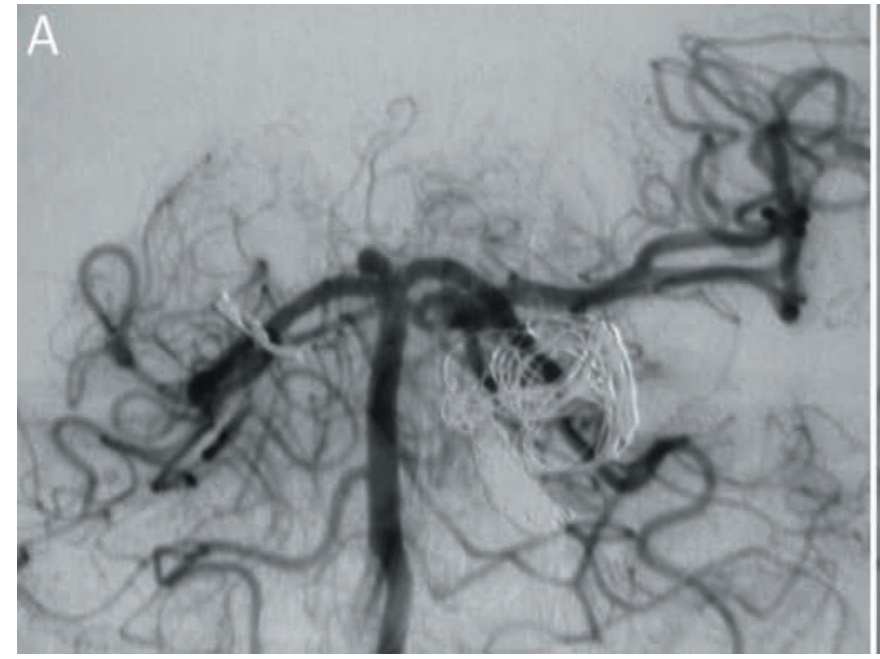

She was submitted to a right pterional craniotomy and microsurgical clipping of the right carotid aneurysm without any complications. Within 2 weeks, endovascular occlusion of left internal carotid artery was performed to treat the giant intracavernous aneurysm after a successful balloon occlusion test for carotid obliteration. Following the endovascular procedure, she was discharged without headache and with a remarkable improvement in the III nerve palsy.

Six months later, she experienced a new sudden event of pain, without loss of consciousness. No new deficits were added, the CT scan showed a subarachnoid hemorrhage and the angiography showed a de novo tip basilar aneurysm (Figure 2A). The patient was submitted to another endovascular procedure for the embolization of the de novo aneurysm and was discharged without new deficits (Figure 2B).

\section{Discussion}

De novo aneurysms were probably first mentioned by Grafi and Hamby in $1964^{4,8}$. They reported on a case of a 39-year-old female with a recurrent subarachnoid hemorrhage due to a de novo aneurysm in the middle cerebral artery.

The development of a de novo aneurysm is rare, with a frequency of $0.84-1.8 \%$ per year $^{8}$. Its formation is probably the result of the interplay between hemodynamic factors and structural weakness ${ }^{3}$. According to Matheus et $\mathrm{al}^{8}$, the pathophysiology of the de novo aneurysm formation involves changes in the vascular connective tissue, such as the presence of hemodynamic stress or formation of a defect in the arterial media or injury to the elastic lamina, corroborating its appearance in patients with multiple aneurisms, or after carotid occlusions, as described in this paper.

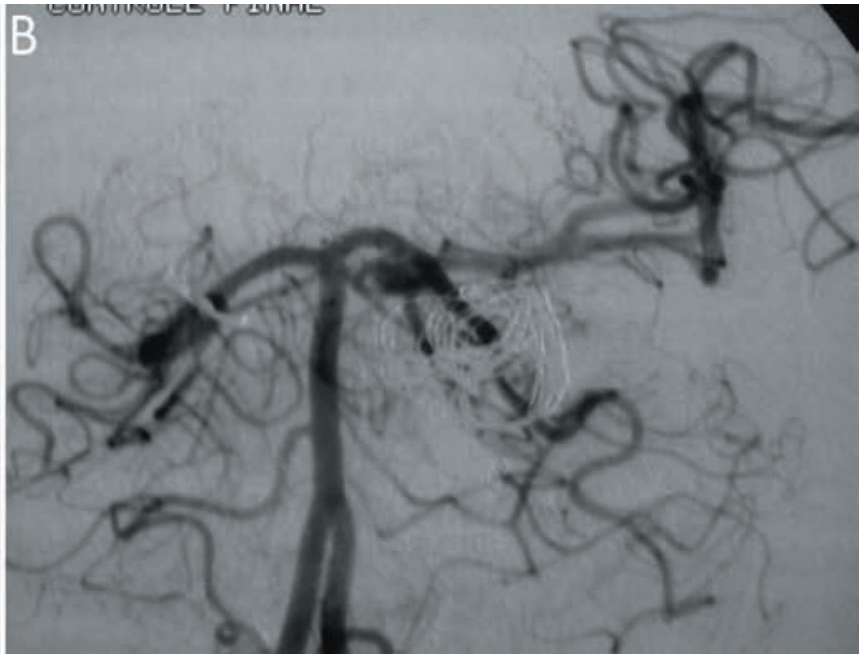

Figure 2. A - Angiography of the de novo tip basilar aneurysm. B - Angiography post-embolization of the de novo aneurysm 
According to Tonn et $\mathrm{al}^{13}$, the mean age of susceptibility to de novo aneurysms was 43.3 (range, 17-69 years). These aneurysms are more commonly observed in the anterior circulation $^{8,13}$, mainly in young patients. The most common site of occurrence is the middle cerebral artery.

Regarding the risk factors, some events have been correlated to aneurysm formation, such as hypertension, female gender, middle age, and cigarette smoking ${ }^{3,5,6,8,14}$. The hemodynamic stress generated by carotid occlusion is what is presumed to induce the de novo aneurysm formation by overloading some vascular territories ${ }^{8,12}$, as had occurred in this particular case. Dyste and Beck ${ }^{2}$ found a range of up to $4 \%$ of de novo formation after carotid ligation, demonstrating a relevant risk factor. None of the de novo aneurysms were located in the posterior circulation in these studies.

A history of multiple aneurysms was associated with de novo aneurysm formation in several past publications, possibly because they speculate on the possibility that multiple parts of the arterial wall may be "pathologic" in patients with multiple intracranial aneurysms ${ }^{3}$. A large late angiographic follow-up of one hundred and two patients treated with microsurgical clipping revealed eight de novo aneurysms found in six patients, five of whom had a history of multiple aneurysms. These data yield an annual risk of $1.8 \%$ per year of de novo aneurysms in surgically treated patients ${ }^{1}$. In 1985, Miller and Hill ${ }^{9}$ reported on six patients with new aneurysm formation previously treated with surgical clipping between 3 and 20 years after the first hemorrhage. Controversially, none had multiple aneurysms.

The elevated incidence of de novo formation in multiple-aneurysm patients raises questions concerning the risk of recurrence of rupturing in aneurysms and the selection of patients to undergo late angiographic studies. Other reports even recommend that young patients be angiographically followed up on, due to the higher risk of the de novo aneurysm, whether they are multiple or not ${ }^{7}$. According to Sprengers et $\mathrm{al}^{11}$, screening all patients within the first 5 years after aneurysm treatment does not seem beneficial, both in terms of preventing SAH and detecting aneurysms in need of treatment.

Actually, the time lapse after which screening for these events could be effective is unknown ${ }^{11}$. Wermer et al ${ }^{16}$, in a study of 610 patients with ruptured aneurysms that were clipped, with a 2-18-year follow-up, found that de novo aneurysms had developed in 3\% of the patients. According to recent publications, the majority of the de novo aneurisms emerge after 3-20 years from the discovery of the initial aneurysm ${ }^{8}$, unlike what occurred in this case.

Because follow-up intervals varied widely, the time of the first development or growth remained obscure ${ }^{11}$. Advances in CT and MRI angiography may be the clue for screening patients under risk of developing the de novo aneurysm.

To conclude, a strict follow-up is necessary, specially in those who are middle-aged, with multiple aneurisms, and in those patients who have an occluded carotid, bearing in mind the possibility of the onset of de novo aneurisms, so that they can be treated in a more satisfactory form, namely prematurely.

\section{References}

1. David, C.A., Vishteh, A.G., Spetzler, R.F., et al.: Late angiographic follow-up review of surgically treated aneurysms. J Neurosurg 1999: 91: 396-401.

2. Dyste, G.N., Beck, D.W.: De novo aneurysm formation following carotid ligation: Case report and review of the literature. Neurosurgery 1989: 24: 88-92.

3. Fujimoto, K., Kimura, R., Iida, J., et al.: De Novo Basilar Top Aneurysm in an Elderly Patient Treated with Guglielmi Detachable Coils. AJNR Am J Neuroradiol 2005: 26: 915-916.

4. Graf, C.J., Hamby, W.B.: Report of a case of cerebral aneurysm in an adult developing apparently de novo. J Neurol Neurosurg Psychiatry 1964: 27: 153-156.

5. Juvela, S., Porras, M., Poussa, K.: Natural history of unruptured intracranial aneurysms: probability of and risk factors for aneurysm rupture. J Neurosurg 2000: 93: 379-387.

6. Juvela, S., Poussa, K., Porras, M.: Factors affecting formation and growth of intracranial aneurysms: a long-term follow-up study. Stroke 2001: 32: 485-491.

7. Koeleveld, R.F., Heilman, C.B., Klucznik, R.P., et al.: De novo development of an aneurysm: case report. Neurosurgery 1991: 29: 756-759.

8. Matheus, M.G., Castillo, M.: Development of De Novo Intracranial Aneurysm in Three Months: Case Report and Literature Review. AJNR Am J Neuroradiol 2003: 24: 709710 .

9. Miller, C.A., Hill, S.A., Hunt, W.E.: "De novo" aneurysms. A clinical review. Surg Neurol 1985: 24: 173-180.

10. Molyneux, A.J., Jerr, R.S.C., Stratton, I., et al.: International Subarachnoid Aneurysm Trail (ISAT) of neurosurgical clipping versus endovascular coiling in 2134 patients with ruptured intracranial aneurysms: a randomised trial. Lancet 2002: 360: 1267-1274.

11. Sprengers, M.E., van Rooij, W.J., Sluzewski, M., et al.: MR Angiography Follow-Up 5 Years after Coiling: Frequency of New Aneurysms and Enlargement of Untreated Aneurysms. AJNR Am J Neuroradiol 2009: 30: 303-307.

12. Timperman, P.E., Tomsick, T.A., Tew, Jr. J.M., et al.: Aneurysm Formation after Carotid Occlusion. AJNR 1995: 16: 329-331.

13. Tonn, J.C., Hoffmann, O., Hoffmann, E., et al.: "De novo" formation of intracranial aneurysms: who is at risk? Neuroradiology 1999: 41: 674-679. 
14. Tsutsumi, K., Ueki, K., Morita, A., et al.: Risk of aneurysm recurrence in patients with clipped cerebral aneurysms: results of long-term follow-up angiography. Stroke 2001: 32: 1191-1194.

15. Van Alphen, H.A.M., Yong-Zhong, G.: Multiple cerebral de novo aneurysms. Clin Neurol Neurosurg 1991: 93: 1318.

16. Wermer, M.J., van der Schaaf, I.C., Velthuis, B.K., et al.: Follow-up screening after subarachnoid haemorrhage: frequency and determinants of new aneurysms and enlargement of existing aneurysms. Brain 2005: 128: 2421-2429.

Marques-Suzuki, M.T.; Brasileiro de Aguiar, G.; Jory, M.; . Marques-Conti, M.L.; Esteves-Veiga, J.C.: De novo basilar tip aneurysm. Case report and literature review. Neurocirugía 2011; 22: 251-254.

Corresponding. Guilherme Brasileiro de Aguiar. Rua Abílio Soares, 121- 84. Paraíso. 04005-000. São Paulo SP Brazil. Email: guilhermebraguiar@yahoo.com.br 